\title{
La emergencia del movimiento feminista en el estallido social chileno
}

\section{The emergence of the feminist movement in the Chilean social explosion}

\author{
Fabiola Ibáñez Carrillo* \\ Fernanda Stang Alva*
}

"La operación historiadora feminista es partisana, es una toma de posición" (Castillo, 2018: 38).

\begin{abstract}
Resumen
Se analizan algunas de las formas en que emergió el movimiento feminista en el estallido social en Chile, centrándose en el proceso de politización no institucional del movimiento y el recurso al cuerpo y las emociones para performar la protesta; aspectos presentes en una genealogía reciente del feminismo, considerando dos hitos: las tomas universitarias feministas de 2018 y la manifestación del 8M de 2019. Se realizó análisis documental de un corpus de notas de prensa sobre los tres acontecimientos y petitorios de las tomas. Proponemos que el feminismo puede ser entendido como un hilo de continuidad que hace inteligible esta serie de procesos que, de otra manera, no podrían ser interpretados: nuevas formaciones y subjetividades políticas, que emergen del desborde de la institucionalidad.
\end{abstract}

Palabras claves: feminismo, política, performance, cuerpo.

\begin{abstract}
Some of the ways in which the feminist movement emerged in the social outbreak in Chile are analyzed, focusing on the non-institutional politicization of the movement and the use of the body and emotions to perform the protest; aspects present in a recent genealogy of feminism, considering two milestones: the feminist university shots of 2018 and the March 8, 2019 manifestation. A documentary analysis of a corpus of press releases on the three events and requests for the shots was made. We propose that feminism can be understood as a thread of continuity that makes intelligible this

\footnotetext{
* Magister en Ciencias Sociales Aplicadas. Socióloga y directora de la Carrera de Sociología de la Facultad de Ciencias Humanas, de la Universidad Arturo Prat (UNAP).

* Doctora en Estudios Sociales de América Latina. Académica investigadora del Centro de Investigación en Ciencias Sociales y Juventud (CISJU), Universidad Católica Silva Henríquez (UCSH).
} 
series of processes that, otherwise, could not be interpreted: new political formations and subjectivities that emerge from the overflow of institutionalism.

Keywords: feminism, politics, performance, body.

Fecha de recepción: Abril 2021

Fecha de aprobación: Diciembre 2021

\section{Introducción ${ }^{1}$}

Los acontecimientos que ocurrieron en Chile en octubre de 2019 y los meses posteriores, constituyen un punto de viraje (Meccia, 2016) en la historia nacional. Pueden entenderse, pensamos, como ese tipo de sucesos que señalan una fecha, que marcan un tiempo, que introducen una discontinuidad, lo que por supuesto no es contradictorio con la presencia de los hilos procesuales que lo ligan a esa historia para la que representan el viraje. Ese tiempo que vivimos el último trimestre de 2019, del que fuimos actores-actrices-testigos, fue uno de esos momentos nítidos en los que la historicidad se manifiesta como acontecimiento.

En este artículo nos proponemos analizar algunas de las formas en que emergió el movimiento feminista en estos sucesos, aludidos como "estallido social", que se produjeron en Chile desde el 18 de octubre de 2019 hasta el inicio de la pandemia de coronavirus en 2020. Más específicamente, nos centraremos en dos dimensiones: el proceso de politización no institucional del movimiento y el recurso al cuerpo y las emociones para performar la protesta, aspectos que emergen de una aproximación genealógica a expresiones recientes del feminismo en el país, considerando dos acontecimientos-hito: las tomas universitarias feministas de 2018 y la manifestación del 8M de 2019.

El abordaje metodológico consideró el análisis documental (Pinto Molina, 1989) de un corpus conformado por notas de prensa seleccionadas por su referencia a los acontecimientos-hito analizados (a saber, las tomas feministas de universidades, la marcha por el 8 de marzo de 2019 y el estallido social), además de petitorios generados durante las tomas feministas de un grupo de universidades seleccionadas considerando que estuvieran presentes instituciones públicas y privadas, laicas y religiosas, de Santiago y regiones -la capital, el norte, el centro y el sur del país- ${ }^{2}$.

La estructura del artículo considera el siguiente hilo argumental: en primer lugar se presentan de manera sintética las principales nociones teóricas que están en la

\footnotetext{
1 Parte de este trabajo se ha beneficiado de revisión bibliográfica y reflexiones realizadas en el marco del proyecto Fondecyt N 3190674 "Migración, precariedad y ciudadanía: de las tácticas de subsistencia a las estrategias de lucha", financiado por ANID, del que la segunda autora de este artículo es investigadora responsable.

2 Se trata de la Universidad de Chile, la Pontificia Universidad Católica de Chile, la Universidad Alberto Hurtado, la Universidad Arturo Prat, la Universidad Técnica Federico Santa María y la Universidad de Concepción.
} 
base de nuestro análisis, luego se describen aspectos salientes del hito central para nuestro interés, el estallido social; paso seguido, se abordan los acontecimientos-hito relevados por el recorrido genealógico del pasado cercano del feminismo en Chile, en orden cronológico, es decir, las tomas universitarias de 2018 y la marcha del $8 \mathrm{M}$ de 2019, realizando en cada caso, primero, una aproximación descriptiva, y luego una analítica. En el segundo caso, se aborda el aspecto más sobresaliente en el que cada uno de estos hitos aporta a la propuesta de lectura de este artículo: las tomas, a la dimensión que hemos denominado politización no institucional, y la marcha del 8M, a la de performatización de la protesta mediante el cuerpo y las emociones. El último apartado propone algunas reflexiones que surgen de este recorrido.

\section{Marco conceptual de referencia}

El análisis que proponemos en este trabajo se apoya en dos herramientas teóricas centrales: por una parte, la noción de subjetivación política delineada a partir de ideas propuestas por Jacques Rancière, y por otra, elementos desarrollados por Adrián Scribano, relativos al cuerpo y a las emociones.

Rancière entiende la subjetivación política como "el acto de la igualdad -o el tratamiento de un daño- de gentes que están juntas, por mucho que estén entre" (2006, p. 22). Para entender esta definición es preciso revisar el modo en que el autor define a la subjetivación, por una parte, y a la política por la otra. El proceso de subjetivación, sostiene, es "la formación de un uno que no es un sí, sino la relación de un sí con otro" (Rancière, 2006, p. 21); la política, en tanto, alude al "terreno del encuentro entre la política y la policía en el tratamiento de un daño" (Rancière, 2006, p. 18). Esta distinción entre política y policía también es fundamental para poder apropiarse de este constructo conceptual. Se trata de dos procesos heterogéneos, explica: el gobierno y la igualdad, respectivamente; la policía "consiste en organizar la reunión de los hombres (sic) en comunidad y su consentimiento, y descansa en la distribución jerárquica de lugares y funciones", la política, por su parte, es "el juego de prácticas guiadas por la presuposición de la igualdad de cualquiera con cualquiera y de la preocupación por verificarla" (Rancière, 2006, p. 17). Dicho en otros términos, un proceso de subjetivación política supone encontrar un "nombre propio" con otros/as, un lugar de enunciación común, en el reclamo de igualdad en alguna dimensión de daño social que nos afecta como un sí-con-otros.

En relación a lo propuesto por Scribano, nos detenemos en dos ideas centrales, sustentadas en la posibilidad de reconocer el cuerpo y las emociones como elementos constitutivos de los fenómenos sociales y, en ese sentido, como aspectos que pueden adquirir centralidad para la comprensión de ciertos fenómenos. Su invitación es a reconocer que el cuerpo es la primera relación que sostenemos con el mundo y que, en ese marco, comprender que el cuerpo "estructura nuestras vivencias y experiencias, donde sensaciones y emociones expresan las diferenciales maneras de sentir-se en el mundo, como las maneras correctas de sentir, dando lugar a las sensibilidades sociales" (Scribano, Cena, Peano, 2012, p. 7). Es decir, entendemos que el cuerpo puede ser un elemento definitorio, para percibir el mundo social y para habitarlo; un cuerpo que trasciende la experiencia y que se ubica en el orden social, 
específicamente, en este caso, en el de las sociedades neo coloniales, donde según Scribano, la explotación y la dominación priman (Scribano et al., 2012). A la vez, el cuerpo posibilita alternativas, en términos de emociones y sensaciones, pudiendo favorecer su expresión o, al contrario, promoviendo su contención. Scribano dirá, en ese sentido, que las emociones pueden ser entendidas dentro de un proceso dialéctico que se establece entre impresiones, percepciones y sensaciones; al respecto, específicamente señala que:

Las impresiones como primera relación con el contexto socio-ambiental, impactan sobre los cuerpos, estructurando las percepciones que los sujetos acumulan y reproducen. Dichas percepciones configuran las sensaciones que los agentes se hacen de aquello que puede designarse como mundo interno y externo... Las sensaciones surgen como resultado y como antecedente de las percepciones que dan lugar a las emociones, como efecto de los procesos de adjudicación y correspondencia entre percepciones y sensaciones. (Scribano et al., 2012, p. 7)

Importa de la propuesta revisada, siguiendo a Scribano (2017), reconocer la existencia de una conexión entre emociones, cuerpo y mundo social. Asimismo, y a la vez, el autor señala y propone reconocer la relación entre cuerpos, emociones y el desarrollo de acciones colectivas (Scribano, 2017); esto es, acciones con intenciones y propósitos colectivos.

En ese sentido, si bien el modelo de sociedad, en sus entramados de poder y estructuras productivas, genera escenarios donde modelar cuerpos y regular emociones es una práctica que configura el modo de la organización social, la posibilidad de cuerpos y emocionalidades que trastocan y tensionan lo social -lo socialmente establecido- aparecen como una alternativa.

Cuerpo mediante, emociones y acciones colectivas en relación. Cuerpos y emociones que son parte integrante de lo social y como componentes que movilizan la organización social.

\section{El estallido social, la chispa de la historia}

Es un complejo entramado de causas, el que fue construyendo el proceso que eclosionó con los acontecimientos del 18 de octubre de 2019 y los que siguieron los últimos meses de ese año, en lo que se ha conocido como el "estallido social" chileno. Más allá de las aprehensiones que genera la idea de "estallido" para aludir a esta emergencia masiva de protestas con diferentes causas específicas, pero que tienen como horizonte común el régimen económico, político y social neoliberal impuesto en Chile durante (y mediante) la dictadura cívico-militar (1973-1990) -que extiende su vigencia hasta nuestros días-, optamos por esta nominación porque entendemos que es una noción que logra plasmar el sentido acontecimiental de estas protestas. Detrás de este sentido está la noción foucaultiana de acontecimiento, es decir:

(...) una forma de proceder en el análisis histórico que se caracteriza, en primer lugar, por una ruptura: hacer surgir la singularidad allí donde se está 
tentado de hacer referencia a una constante histórica, a un carácter antropológico o a una evidencia que se impone más o menos a todos (...). En segundo lugar, esta forma de proceder se caracteriza también por hallar las conexiones, los encuentros, los apoyos, los bloqueos, los juegos de fuerza, las estrategias que permitieron formar, en un momento dado, lo que luego se presentará como evidente. (Castro, 2004, p. 10)

Es decir, la noción de acontecimiento logra articular, a la vez, el carácter singular de ese hecho histórico con el ensamblaje progresivo de sucesos y procesos que llevaron a su emergencia (materializados en esas conexiones, juegos de fuerza, bloqueos y apoyos, estrategias...). En esa línea, como sostienen Basaure y Joignant (2019), lo ocurrido en el estallido revela elementos de continuidad con movimientos de protesta anteriores, concretamente, el rol protagónico de la "cuestión redistributiva" como demanda transversal; pero también presenta aspectos distintivos: la magnitud de la explosión; la ausencia de actores representados en las demandas y, a su vez, de demandas bien definidas y estructuradas, y el carácter más difuso de la separación entre "formas legítimas-no violentas" y "formas no legítimas-violentas" de la protesta.

El acontecimiento-estallido se inició con un hecho incidental, "nimio", según varios cronistas: el alza de 30 pesos (0,04 dólares) del pasaje del tren subterráneo (el Metro de Santiago), en medio de desafortunadas declaraciones de ministros y funcionarios de gobierno que caldearon los ánimos, llamando por ejemplo a "madrugar" para usar el servicio en el horario en el que el pasaje es más económico. Esta alza fue recogida por uno de los lemas más difundidos del estallido, reproducido en grafitis y pancartas: "no son 30 pesos, son 30 años", frase pronunciada en esos días por Esteban Maturana, dirigente gremial de la salud pública (Waissbluth, 2020), en alusión a las tres décadas del retorno de la democracia, durante las que no se han modificado las estructuras del régimen neoliberal heredado de la dictadura, que ha tenido, entre otras consecuencias, una sociedad profundamente desigual. Frente a este incremento del pasaje, los y las estudiantes secundarios/as iniciaron una evasión masiva en el Metro, a la que se respondió con una violenta represión.

A esta "chispa" inicial, le siguieron sucesos que han sido difundidos a nivel internacional: marchas multitudinarias a lo largo del territorio nacional, entre ellas la más numerosa de la historia del país, una semana después (el 25 de octubre), de carácter pacífico. Manifestaciones en las que confluyen la indignación, la rabia, junto con esa específica euforia que surge de descubrir que este sentir es colectivo. Marchas reprimidas por las fuerzas policiales, cometiendo violaciones de derechos humanos que fueron denunciadas por diversos organismos. Entre ellas, traumas oculares por el uso de balines, que generan una indignación expresada en un gesto metonímico: cubrirse un ojo con la mano para manifestar la adhesión al movimiento.

Cacerolazos masivos, una explosión de grafitis que traducen en textos e imágenes reflexiones y sentires largamente mascullados y plagados de humor e ironía. La música es otro lenguaje protagónico, con algunos temas que se convirtieron en emblemas, como "El derecho de vivir en paz", de Víctor Jara, o "El baile de los que sobran", de Los Prisioneros. Las performans se abrieron paso en las marchas, generalmente de la mano de grupos feministas, y entre ellas, una que recorrió el 
mundo como reguero de pólvora: "Un violador en su camino", del Colectivo Las Tesis. La sociedad vivió además un estado asambleario, con cabildos territoriales discutiendo sobre los cambios que la calle pedía de forma difusa, pero arrolladora, y que poco a poco empezaron a canalizarse en la demanda de un cambio de la Constitución de 1980, otra pesada herencia del régimen dictatorial. Hubo también saqueos y destrozos. Así también, enfrentamientos sistemáticos entre carabineros y otro actor emergente del estallido, la llamada "primera línea", grupos de jóvenes que enfrentaban la represión estatal de manera sistemática.

El acontecimiento-estallido puede interpretarse como un momento cúlmine de un proceso de creciente movilización y conflictividad social en el país, que algunos/as autores/as fechan por 2004 y 2005, con diversas demandas sectoriales (educación pública, salud, previsión social, medioambiente, derechos de las mujeres y de los pueblos indígenas, entre otras) que generaron manifestaciones con alta convocatoria (Candina Polomer, 2019), y otros/as en un "despertar ciudadano" en 2011 (Basaure y Joignant, 2019), en el clímax de las protestas estudiantiles por educación pública, gratuita y de calidad. Todas estas protestas, dice Candina Polomer, "compartieron una crítica profunda al modelo económico y político neoliberal y al Estado subsidiario, y demandaron políticas solidarias y redistributivas y una mayor participación en la política y sus decisiones" (Candina Polomer, 2009, p. 57). Además, observan Basaure y Joignant en su análisis, no fueron procesadas institucionalmente en la amplitud y profundidad de sus planteos, ubicando en ello un importante factor explicativo del estallido: "Se ha mantenido, en términos generales, la respuesta represiva e intolerante respecto de la movilización, lo que ha contribuido a la radicalización de ésta" (Basaure y Joignant, 2019, s/p).

Nuestro propósito en este artículo, es detenernos en dos aspectos de este acontecimiento en los que, desde nuestra propuesta de lectura, ha tenido una incidencia significativa el movimiento feminista chileno: la politización no institucional del movimiento, ligada a esta ausencia en cierta forma deliberada de actores/actrices representativos/as -ningún partido político se atrevió a aparecer con sus banderas en medio de las manifestaciones, por ejemplo- y el recurso al cuerpo y las emociones para performar la protesta. Para ello, realizaremos una suerte de genealogía de dos acontecimientos-hito, que nos parecen relevantes para ilustrar el punto de nuestra propuesta analítica: las tomas universitarias feministas de mayo de 2018, y la manifestación del 8M de 2019.

\section{Tomas universitarias: la articulación de feministas y estudiantes}

El 2018 fue un año clave en Chile para la articulación del movimiento feminista con el estudiantil -actor político de resistencia protagónico en el escenario de la posdictadura en el país (De Fina y Figueroa, 2019)-, articulación relevante para entender la forma que tomará el estallido social. Entre abril y julio de ese año se sucedieron una serie de "tomas feministas" de universidades, que alcanzaron a 26 instituciones académicas según fuentes periodísticas (CNN Chile, 7/12/2019) y que levantaron como principales demandas, medidas contra el acoso y abuso sexual dentro de estas instituciones. Además, diferentes expresiones de lo que se nomina 
como "educación no sexista" -desde la incorporación obligatoria de ramos o materias que aborden temas de género, hasta la equidad de género en la distribución de puestos docentes, pasando por una incorporación sistemática de textos de autoría femenina en las bibliografías, el uso del lenguaje inclusivo, entre otros aspectos-:

Quienes hoy se movilizan buscan generar una política institucional firme respecto a la violencia de género. En este sentido, la construcción de protocolos que subsanen con eficacia las problemáticas derivadas del machismo dentro de la comunidad universitaria. Estas dos demandas, mínimas y básicas, se comprenden como una necesidad transversal para la educación chilena en todos sus grados. (Petitorio Toma Feminista Universidad Alberto Hurtado, 2018)

El sexismo en la educación es palpable en el currículum educativo, así como también en las prácticas dentro y fuera del aula. En efecto, observamos, por ejemplo, bibliografía compuesta mayoritariamente por autores hombres en todos los cursos de todas las carreras de la Universidad; desconocimiento en temáticas de género del cuerpo docente lo que conlleva a comentarios y conductas machistas e invisibilización del conocimiento producido por mujeres. (Petitorio Unificado Asamblea de Mujeres de la Universidad de Chile, 2018)

El acontecimiento-tomas partió el 17 de abril en la Universidad Austral de Valdivia, debido a la indignación de las estudiantes por una indemnización millonaria a un docente despedido por la denuncia de acoso sexual de una funcionaria (La Tercera, 2018). A partir de allí, otras universidades fueron paralizadas por estudiantes mediante tomas que, en su mayoría, se declararon separatistas, es decir, no permitieron la participación de estudiantes varones, o bien la restringieron. La adhesión fue tan amplia que hasta en la sede de la Pontificia Universidad Católica se produjo una toma, algo que no ocurría desde 1967 (CNN Chile, 7/12/2019).

Las demandas del movimiento, plasmadas en petitorios que surgieron de asambleas, se concentraron como decíamos en medidas respecto del acoso y abuso sexual y en la necesidad de una educación no sexista. Las estudiantes, visibilizaron prácticas del poder patriarcal, que han atravesado históricamente la educación superior en el país (y, obviamente, no solo en Chile) y de alguna manera, equipararon esas exigencias al reclamo de gratuidad, que venía levantando el movimiento estudiantil desde comienzos de la década de 2000.

Algunos trabajos que han analizado este movimiento (De Fina y Figueroa, 2019; Ponce, 2020) coinciden en señalar, por una parte, la existencia de un escenario de "efervescencia" del feminismo a escala internacional, pues en los dos años previos se habían estado generando movimientos como el pañuelazo en la Argentina, demandando legislación por el aborto libre, gratuito y seguro; el \#Ni una menos, el MeToo; entre otros. Por la otra, establecen el anclaje de estos acontecimientos en el desarrollo histórico del feminismo a escala nacional, y remiten también a la fuerza transformadora que ha tenido el movimiento estudiantil en Chile, por lo que no resulta casual el escenario de este acontecimiento. 


\section{Politización no institucional y subjetividades políticas desbordadas}

Uno de los aspectos sobresalientes del "estallido social", como señalábamos y que no tardó en llamar la atención, tanto de analistas como de observadores en general, fue la ausencia de representantes definidos y sobre todo, de consignas, banderas, imágenes o vocerías asociadas a partidos políticos, un rasgo-proceso que aquí aludiremos como politización no institucional del movimiento. En efecto, columnas de opinión en la prensa y mensajes en redes sociales tematizaban este aparente "carácter inorgánico" del movimiento (Basaure y Joignant, 2019), una suerte de acefalía y espontaneidad que, a la vez que fascinaba a algunos/as, despertaba inquietudes relativas a las formas en que se podrían canalizar las demandas, ante una ausencia de interlocutoras claras.

Durante los acontecimientos iniciados el 18 de octubre de 2019 (18-O), el único rostro visible, que de algún modo articulaba muchas de las voces que se habían ensamblado en este acontecimiento, fue la Mesa de Unidad Social, una agrupación de 182 organizaciones sociales de diverso tipo, provenientes de un amplio y heterogéneo abanico de ámbitos y sectores ${ }^{3}$. Pero, sin dudas, el movimiento excedía a este actor colectivo, lo desbordaba, y desconcertaba las miradas convencionales sobre los procesos sociopolíticos. Como observan Insunza y Pérez:

No había ni manifiesto ni programa, claro que no. Pero al poco andar entendimos que se trataría de un movimiento que iba a instalar sus ideas fuerza desde estrategias no convencionales en relación a una práctica gubernamental o histórica de la política, las instituciones y 'los políticos'. (Insunza y Pérez, 2020, s/p)

Era y es claro, de todos modos, que hay dos movimientos que adquirieron un carácter protagónico para alimentar este caudal desbordante, el estudiantil y el feminista, que tuvieron un rol central en la definición del perfil de estos acontecimientos:

En esta intersección entre repertorios de acción de movimientos estudiantiles y feministas, locales y transnacionales, se crea algo nuevo en Chile, de extrema vitalidad que va a cuestionar, desafiar, tensionar y transformar la cultura política en este país. (De Fina y Figueroa, 2019, p. 62)

El análisis que proponemos en este apartado, sugiere que la politización no institucional del estallido social, se alimenta en buena medida del movimiento feminista y en particular de los rasgos que fue adquiriendo el feminismo en su historia nacional, que habían emergido en formas específicas durante los dos hitos previos que consideramos en este análisis (tomas y $8 \mathrm{M}$ ), con lo cual es posible establecer ciertas líneas de continuidad.

Si se sigue el análisis que realiza Julieta Kirkwood, del vínculo entre feminismo y partidos políticos en Chile, se advierte la temprana relación problemática que se establece entre ambos:

\footnotetext{
3 Puede consultarse el sitio web https://unidadsocial.cl/organizaciones-convocantes/ para conocer las organizaciones que forman parte de la Mesa.
} 
(...) tanto el PCF [Partido Cívico Femenino], el MEMCH [Movimiento Pro-Emancipación de las Mujeres de Chile] y todas las organizaciones femeninas del período, hasta años después del voto, constantemente afirmarán la no identidad con partidos o ideologías políticas. Se expresa una relación ambigua con la política de parte de las mujeres de izquierda y derecha (derivamos su pertenencia de sus pronunciamientos y opciones): todas la niegan; todas quieren representar a las mujeres al margen -formalmente- de los partidos políticos. No es de extrañar, entonces, la posición enormemente contradictoria de las mujeres con la política, y más aún con los partidos. (Kirkwood, 2019, p. 131)

"El feminismo en Chile ha tenido un carácter de permanente incomodidad con respecto a un orden jurídico-político", afirma de modo concluyente Follegatti (2018, p. 82). Ciertamente, esta nota histórica a escala nacional converge con las características de movimiento social que tiene el feminismo a escala internacional y también, con la creciente deslegitimación de los partidos políticos en las últimas décadas a nivel latinoamericano en general y chileno en particular (PNUD, 2019; Waissbluth, 2020). En efecto, la deslegitimación de los partidos políticos ha crecido de manera notable desde la recuperación de la democracia. La encuesta "Auditoría a la Democracia", desarrollada por el Programa de las Naciones Unidas para el Desarrollo (PNUD) desde 2008 en el país, muestra que los partidos políticos, junto con el Congreso y los tribunales de justicia, son las tres instituciones respecto de las cuales más han crecido las percepciones negativas en el período 2008-2018 (PNUD, 2019).

Aun así, este rasgo histórico del feminismo chileno -es decir, la desconfianza y lejanía respecto de los partidos políticos, y las formas convencionales de la política-, parece decisivo en sus formas de presencia e incidencia y por ende, en su impacto específico en el 18-O. Las tomas universitarias feministas de mayo de 2018, a su vez, constituyen un precedente claro de la forma que le da el movimiento al estallido, tanto en su politización no institucional, como en la escenificación performática de la disputa.

Respecto del primer punto, es decir, la politización no institucional, Nelly Richard observa, en su análisis de las tomas, el rebasamiento que ejercieron las consignas sobre los canales institucionales:

Las tomas feministas de mayo 2018 lograron que la palabra 'feminismo' diversificara sus frentes de antagonismo (contra el patriarcado, contra la educación sexista, contra la Iglesia, contra el neoliberalismo, contra las autoridades de gobierno, etc.), volviendo sus reclamos y demandas inabarcables en los términos formales de la política administrativa. (Richard, 2018, p. 118)

En los petitorios analizados se establece claramente esta articulación desbordante de las demandas:

(...) las lógicas actuales de nuestra Universidad, sustentadas en los estatutos, reproducen un modelo neoliberal y patriarcal palpable en la educación que imparten sus reglamentos, financiamiento y jerarquía existente 
entre estamentos, donde inherente a ésta se encuentra la cuestión de género. (Petitorio Unificado Asamblea de Mujeres de la Universidad de Chile, 2018)

La "cadena asociativa y derivativa de significantes de lucha" que fue construyendo el movimiento de las tomas, dirá la autora, que no se agota en una demanda práctica, hizo muy difícil su burocratización institucional (Richard, 2018). El estallido social, hasta su pausa pandémica, parece haber hecho eco de este aporte del feminismo en clave nacional, cristalizado en el hito-tomas: la amplitud y heterogeneidad de la demanda y la multiplicidad de planos a los que tocaron esos reclamos, no podía encontrar voz en los partidos institucionalizados y cuando el concierto adquirió alguna voz, de modo parcial y episódico, tomó la polifonía de un actor como la Mesa. Es cierto que una parte de ese movimiento se canalizó finalmente hacia un objetivo determinado: un plebiscito en el que se debía decidir si la ciudadanía aprobaba o rechazaba un cambio de la Constitución de 1980, elaborada durante la dictadura de Pinochet ${ }^{4}$, pero el modo en que han quedado posicionados los partidos políticos, frente a este proceso, también ha implicado un duro cuestionamiento hacia ellos. La fuerza que ha cobrado en la opinión pública la discusión sobre la participación de los/as candidatos/as independientes en la convención constitucional, es una prueba palpable.

Este desborde, o amplitud, de los significantes de lucha, remite a otro aspecto importante para pensar esta arista de la politización no institucional del movimiento de las tomas, que es cierta imposibilidad de adscribirle una identidad particular, como observa Follegatti:

Es por esta razón que el feminismo les resulta incómodo a las estructuras tradicionales de la política, pues sus claves, lugares de enunciación y problemas políticos parecen no hacer mella frente a categorías que colocan los conflictos políticos vinculados a problemas homogéneos o bien, signados en una identidad particular, como si la identidad confiriera de por sí una particularidad política determinada. (Follegatti, 2018, p. 80)

Esta multiplicidad, en alguna forma inasible por categorías identitarias, estuvo representada no solo por la diversidad y amplitud de causas de lucha de las tomas, sino también por la heterogeneidad de actores del movimiento: "las distintas asambleas de mujeres y disidencias enfrentaron serias dificultades para poder articularse a través de una coordinación que permitiera instalar las reivindicaciones feministas a nivel nacional" (Archivo Nacional, s/f). Esas dificultades de articulación estaban relacionadas, como han señalado algunas de sus protagonistas, con un contundente cuestionamiento a la representación institucional del movimiento (Archivo Nacional, s/f) ${ }^{5}$, que derivó, por ejemplo, en la decisión de realizar vocerías rotativas de las asambleas. Este constituye un tópico claro del feminismo a escala nacional: la Red

\footnotetext{
4 Celebrado el pasado 25 de octubre, con triunfo de la opción "Apruebo" (78,3\%), y de la modalidad "convención constituyente" (miembros serán elegidos en su totalidad por la ciudadanía), desechando la opción de convención mixta (50\% parlamentarios y 50\% ciudadanos elegidos). La derrota de esta segunda opción es otra evidencia de la deslegitimación generalizada de representantes, políticos y partidos.

5 Véase también el trabajo de Miranda y Roque (2019), que analiza estos dilemas en el seno de una de las tomas emblemáticas del movimiento, la de la Pontificia Universidad Católica.
} 
Chilena Contra la Violencia hacia las Mujeres sostenía, por ejemplo, en un análisis del estallido social en perspectiva feminista:

La acción política de las mujeres ha planteado nuevas formas de organización que cuestionan las jerarquías, los liderazgos individuales y, en definitiva, las formas patriarcales. Esta politicidad de las mujeres potencia la deliberación colectiva, los diálogos horizontales y propicia espacios de cuidado colectivo. (Red Chilena Contra la Violencia hacia las Mujeres, 2019, s/p)

Otra vía por la que emergió este cuestionamiento a las formas y canales institucionalizados para la expresión de las demandas fue la escritura colectiva de los petitorios:

(...) es una escritura colectiva. Los lectores escandalizados por el supuesto anonimato de comunicados y petitorios no entienden las condiciones particulares de producción textual. Estos petitorios se escriben de forma colaborativa y horizontal. En las asambleas, se planifican de forma oral los principales temas, reclamos y argumentos. Al comienzo son punteos, viñetas, listas. Luego, usando herramientas informáticas y las estigmatizadas redes sociales, se amplían y reformulan fragmentos durante días hasta lograr un texto difícil de refutar. Puede ser que algunas mujeres lideren temporariamente la elaboración de los textos, pero no quedan huellas de su autoría, porque es el reclamo de un colectivo social. (Navarro, 2018, s/p)

Esas transformaciones concretas de los modos de hacer y pensar la política, de los que el feminismo ha sido actor crucial, cuajaron en expresiones durante el estallido social. Son esos modos, a través de la politización no institucional de los reclamos, los que nos llevan a preguntarnos si acaso el 18-O, no ha implicado una forma de ensamblaje del movimiento feminista, en un proceso más amplio de repolitización de lo social en el país. Aludimos a la idea de ensamblaje que proponen De Fina y Figueroa (2019), siguiendo a otros autores, para pensar el feminismo, y que se refiere a:

(...) un proceso no lineal de composición contingente de múltiples agentes, discursos e instituciones, cuyo resultado es la emergencia de entidades sociales que conforman la realidad social en un tiempo y espacio determinados". Esa interacción genera "'propiedades emergentes' que no remiten a las capacidades específicas/intrínsecas de las partes, 'sino a las producidas por su interacción, que se dan sólo bajo su dominio. Las propiedades emergentes tienen la capacidad, cuando se territorializan, de influenciar a las partes que la componen, singularizándose y diferenciándose ontológicamente de las mismas'. (De Fina y Figueroa, 2019, p. 61-62)

Este constructo conceptual resulta bastante iluminador de los sucesos que se han nominado como estallido social: un ensamble de actores, organizaciones y movimientos, el estudiantil y el feminista, entre varios otros, cuyo resultado emergente es un todo que supera, que excede, las propiedades y posibilidades de sus partes, que resultan transformadas en esa interacción contingente. 
Las transformaciones de los modos de pensar y actuar la política a las que aludimos, son una materialización de los emergentes de ese ensamblaje, que se expresan, por ejemplo, en una rica y desafiante cantera de intervenciones en y del espacio público:

En el mayo feminista la política se vivió en asambleas, círculos de mujeres, talleres de ginecología natural, clases de danza, etc., instalando nuevos códigos políticos que diluyeron las fronteras entre lo público y lo privado, entre el discurso y la práctica. (Archivo Nacional, s/f, s/p)

Con un hilo de continuidad, el movimiento imprimió sus formas de expresión al estallido, desde los pañuelos violetas hasta la performance de Las Tesis, desde los cuerpos desnudos pintados con consignas hasta las imágenes de vírgenes profanas pegadas en las paredes.

El estallido partió antes, entre varias vías, a través de los $8 \mathrm{M}$ previos, con las tomas feministas: "El estallido feminista articuló distintas organizaciones de mujeres, a nivel vecinal, estudiantil, sectoriales y de profesionales, un nuevo tejido social que se movilizó como antesala al 180" (Segovia, 2020, s/p). Ese caudal potente desbordó en el estallido. Y esta idea de desborde, que adquiere relevancia en el análisis de las tomas feministas y del estallido, parece clave para pensar las nuevas subjetividades políticas que han estado construyéndose, al hilo del feminismo, entre otros movimientos, y que toman protagonismo en el 18-O: "El colapso de un orden implica que ya hay un acumulado de saberes, prácticas y subjetividades que darán lugar a otro cuerpo para la política", dirá Alejandra Castillo (2019), en un aspecto de estas nuevas subjetividades políticas que abordaremos en los próximos apartados (el del cuerpo).

Nos interesa aquí poner en escena la idea de nuevas subjetividades políticas, al hilo de la propuesta de Rancière, articulada a esta noción de desborde como el momento productivo, movedizo, por el que estas nuevas subjetividades se están conformando. Cuáles son las formas que están adquiriendo estas nuevas subjetividades, es algo que toca explorar de modo sistemático y no es este el espacio para ello. Aquí nos interesa reflexionar, de modo exploratorio, sobre el papel central que ha jugado el feminismo en las transformaciones de la política y sus sentidos y por lo tanto, en los procesos de subjetivación política.

Según Didier Fassin (2018), "lo más significativo de los últimos decenios fue interrogarse por el objeto político mismo" (p.16), a partir de una idea central inspirada en Marx y Foucault: "lo político no es algo dado de antemano, sino el producto de la acción humana" (Fassin, 2018, p. 16). Esta idea fue alimentada, dice el autor, por las movilizaciones sociales, los estudios poscoloniales y el feminismo, que es el punto que nos interesa enfatizar. En esa línea, y parafraseando a Simone de Beauvoir, Fassin dice que el género y la sexualidad no son objetos políticos en sí mismos, sino que llegan a serlo. Con su consigna "lo personal es político", el movimiento abrió paso a una politización de lo privado (Follegatti, 2020) y como consecuencia, a un cambio en el estatuto de lo público. Esos constituyeron hitos fundantes de este cuestionamiento del significado de lo político de los últimos decenios y también de sus formas, por ejemplo, a partir de la interpelación a los modos patriarcales de lo político, y el recurso 
a formas comunitarias de hacer política (Oyarzún, 2020). Es decir, las demandas por la igualdad, alcanzaron esos ámbitos y dimensiones antes no problematizados en términos de daño social y de ese modo, el sí-con-otros, amplió sus posibilidades articulatorias. De ese modo, el nombre propio contingente (una idea de pueblo resignificada, en el sentido que excede el lugar de enunciación de un sujeto de clase) y el nombre que toma la demanda por el daño (la dignidad), desbordaron las formas institucionales de subjetivación política y el feminismo ha sido central en ese desborde.

Entonces, para sintetizar, consideramos que el feminismo ha jugado un rol central en el cuestionamiento de los sentidos de "lo político" y por ende, en las transformaciones de los procesos de subjetivación política. Una de las traducciones de este proceso más amplio ha sido un cuestionamiento a ciertas cristalizaciones institucionales de lo político: los partidos, la ciudadanía, etc., y como contrapartida, una politización de la vida y del cuerpo (Fassin, 2018), dominios a los que se extendió la demanda por la igualdad, en nombre del daño. Ese marco explica lo que llamamos la dimensión de politización no institucional, que entendemos como una coagulación específica y concreta del feminismo chileno en el estallido social, y que revela su hilo de continuidad con los hitos previos que estamos analizando: las tomas universitarias y el $8 \mathrm{M}$.

\section{El 8M y el feminismo que altera la marcha}

La movilización más grande en la historia (El Desconcierto, 2019), junto a otras variantes posibles, es la frase que se repite en los medios para describir y calificar la marcha realizada el 8 de marzo de 2019 en nuestro país. Movimiento e historia, como dos elementos conjugados para hablar de este acontecimiento, el 8M. Marcha que podemos entender como una declaración de un malestar y de una esperanza, que, por una parte, se visibiliza como movimiento y agitación pública y que, por otra, se contextualiza en una historia que le precede, asociada a procesos y propuestas feministas con una larga data en nuestro país.

En ese sentido, las últimas expresiones del movimiento feminista, entre las que se encuentra el 8M y siguiendo a Zerán, pueden ser entendidas como:

(...) un continuo mediante el cual las históricas reivindicaciones de mayor democracia, libertad e igualdad dialogan no sólo con parte de los feminismos actuales, sino con una tradición de lucha de precursoras feminista de siglos anteriores. (Zerán, 2018, p. 10)

Resulta fundamental, así, reconocer la existencia de un movimiento que, siendo diverso en sus énfasis, ha logrado permanencia y presencia en nuestro país. Entonces, aunque con la posibilidad de un desarrollo con mayor o menor intensidad, planteamos la existencia de un proceso político feminista que da contexto al $8 \mathrm{M}$.

Por esta razón y siguiendo lo que propone Castillo (2018), sugerimos que las últimas manifestaciones del movimiento feminista, no deben ser entendidas como prácticas singulares; al contrario, se encuentran conectadas a antecedentes previos y constituyen partes de un proceso y de un quehacer feminista. La mirada que pone el 
acento en la excepcionalidad y subraya la eventualidad, ignora las relaciones posibles y vuelve la expresión feminista al terreno de lo incierto. "¿Qué produce el olvido positivista? Este olvido vuelve transparente el cuerpo del feminismo. Le arrebata el cuerpo, los cuerpos que el feminismo ha venido narrando" (Castillo, 2018, p. 45). Lo anterior, invisibiliza la posibilidad de una política feminista.

Es en ese proceso y bajo este punto de vista, que proponemos entender la expresión pública del movimiento de estos últimos años. En ese esfuerzo, podemos reconocer que, específicamente durante el año 2016, se observa un aumento de acciones de carácter feminista, por ejemplo, vinculadas al movimiento \#NiUnaMenos (Reyes-Housholder y Roque, 2019, p. 194). Estas manifestaciones se sostienen en el tiempo y progresivamente, adquieren un carácter masivo y nacional, que visibiliza diversas demandas; de este modo, el año 2018 la intensidad del movimiento es clara:

Además de las tomas y paros en las universidades, fueron convocadas marchas feministas en diversas ciudades del país durante el período del primer semestre de 2018, todas con masiva asistencia e impacto en la sociedad chilena. El 11 de mayo se realiza una gran marcha feminista, convocada por la Coordinadora Ni Una Menos de Chile, contra la 'cultura de la violación'. El 16 de mayo, la Confederación Nacional de Estudiantes de Chile (CONFECH) convoca a marchar por una educación no sexista, con el objetivo de dar a conocer el rechazo del estudiantado frente a las violencias machistas. Participaron de la manifestación distintos movimientos en ciudades del norte, centro y sur del país, como lquique, Valparaíso, Concepción, Temuco y Valdivia. (De Fina y Figueroa, 2019, p. 59).

Entonces, parece necesario reconocer que el $8 \mathrm{M}$ del 2019, es parte de un proceso que se entiende como un continuo, en el que -pese a las diferencias y a la necesidad de hablar de feminismos- existen elementos comunes que articulan una gran demanda: desmantelar las relaciones desiguales entre hombres y mujeres y desnaturalizar la organización social patriarcal.

En ese contexto, la Coordinadora Feminista $8 \mathrm{M}$, previo a la gran marcha, plantea una serie de demandas, entre ellas, el fin a la violencia en sus diversas expresiones, trabajo digno, derecho a la vivienda digna, nueva ley de migraciones, derecho al aborto, justicia y verdad ante violaciones a los derechos humanos, ley de medios con perspectiva feminista, fin al extractivismo, tipificación de los crímenes de odio, educación como derecho social (Coordinadora Feminista 8M, 28/2/2019); todas estas peticiones se trasladan a las calles y donde, masividad a cuestas, dos elementos se vuelven centrales en la protesta pública feminista: el cuerpo y las emociones.

Durante el $8 \mathrm{M}$, las marchas poco tuvieron de tal. Los recursos visuales, los sonidos, los movimientos para llamar la atención, desbordaron las calles, pero también excedieron la idea de marcha, entendida como un recorrido uniforme y homogéneo. De este modo, y siguiendo a Urzúa, podemos señalar que en la protesta pública se pueden observar otros componentes: "Los recursos expresivos no se agotan en el uso de códigos lingüísticos. En la disputa por la visibilidad, estos adquieren diversas formas asociadas a una manera específica de emplear el cuerpo" (Urzúa, 2019, p. 
120). Aparece, entonces, una diversificación de las estrategias, con expresiones híbridas e intensas y donde los cuerpos son parte central de la movilización.

Podemos hablar, por tanto, de un proceso de performatización de la protesta feminista, de procesos creativos para representar el descontento y para demandar y exigir cambios; ejercicios estéticos donde cuerpo y emocionalidad son parte y base de la expresión. Los medios resaltan:

Marcho por mis hijas, nietas y sobrinas", decía el modesto cartel, en cartulina celeste y pintado con plumón, que se armó Alba, de 66 años, y que portaba brazos en alto, como si se le fuera la vida en ello.

Hasta el miércoles se habían confirmado manifestaciones en más de 50. En Santiago había bailes, batucadas, globos, payasos y pancartas, pero, por sobre todo, ellas. Grandes y chicas. Como una sola voz. (La Tercera, 2019)

Colores verdes y morados, carteles y lienzos. Caras cubiertas y torsos descubiertos. Tambores y cantos. Bailes y gritos. Cuerpos y un mismo cuerpo. Desbordes e intensidad, momento excepcional. Rabia y alegría. Demanda y proclama. Movilización y movimiento. Lo privado puesto en lo público: cuerpos reconocidos y ya no negados, porque es desde los cuerpos que se levanta la demanda; emocionalidad que acompaña, porque es desde una vida sin miedo que se sostiene la demanda.

\section{La performatización de la protesta}

Octubre del 2019 aparece y no parece antecedido; irrumpe. El estallido social ha sido nombrado desde lo inesperado, como algo de lo que no se tiene precedentes. Proponemos, sin embargo, en lo que sigue, que parte del carácter que distingue al 18$\mathrm{O}$, especialmente en lo referido al modo en que se manifiesta y exterioriza la protesta, proviene del movimiento feminista, concretamente, de las expresiones que se enmarcan dentro del $8 \mathrm{M}$ y como se señalaba, de la politización no institucional del movimiento.

Específicamente, el $8 \mathrm{M}$ del 2019, como hito enmarcado en la creciente expresión y manifestación pública del movimiento feminista, contiene en su desarrollo, entre otros aspectos, elementos que pueden ser entendidos como performance. Por performance, vamos a entender las "diversas prácticas y eventos como danza, teatro, rituales, protestas políticas... que implican comportamientos teatrales, ensayados 0 convencionales, aptos para esos eventos" (Taylor, 2015, p. 34). Expresiones todas, puestas en lo público, mediadas por los cuerpos (Citro, 2009), construidas desde y con diversos materiales que trascienden lo textual y que se corporalizan; pudiendo adquirir características que convergen en "actuaciones que poseen un tiempo limitado, un comienzo y un final, un programa organizado de actividad, ejecutantes y audiencias, y que se desarrollan en un lugar y ocasiones determinada" (Citro, 2009, p. 31). Cuerpos y emociones como componentes de estas expresiones y en este caso, el del 8M, entendidas como fundamentos políticos de una demanda, que cuestiona la idea de consenso. 
En base a lo señalado, queremos sugerir que la puesta en escena que proponen los feminismos, esta performatización de la protesta, ese elemento tan característico y destacado por los medios, alcanza el estallido social. En ese sentido, estamos proponiendo establecer una relación entre el movimiento feminista, sus propuestas, expresiones y características, con los hechos ocurridos durante octubre del 2019; una lectura que recoge desde una continuidad, las propuestas y revueltas del movimiento feminista, en particular en lo relativo al cuerpo y emociones y que alcanza el 18-O, una conexión que liga con un magma esta coagulación emergente del acontecimiento.

Un cuerpo cercado por lo biológico, pero que trasciende ese espacio y se visibiliza desde lo social; un cuerpo como territorio, con posibilidad de ser entendido, tanto desde las prácticas sociales como desde su representación. Cuerpo y no corporalidad, por tanto, un cuerpo situado y no sólo experimentado y vivido. Un cuerpo que se ubica en una estructura social y que, como señala Le Breton (2002), "en cualquier sociedad humana, está siempre significativamente presente. Sin embargo, las sociedades pueden elegir entre colocarlo a la sombra o a la luz de la sociabilidad" (p. 122). Cuerpo, entonces, presente en el $8 \mathrm{M}$ y puesto en el estallido. Desde ahí, el cuerpo puede ser entendido desde una concepción rupturista o disruptiva y por tanto, en el terreno de lo que no se controla, lo que desborda, lo que interrumpe. Detrás de esto, tal vez, se vislumbra la dicotomía de siempre, esa que se fortalece con la modernidad y que enfatiza distinciones y distancias insalvables, entre cuerpo y mente/razón y otras posibles divisiones. Esa que se configura, por tanto, oponiendo y poniendo el cuerpo del lado de la no nación y de la negación del estado y sus instituciones circundantes, incluyendo los partidos políticos, como ente regulador o, al menos, articulador, de la acción política planificada y de la posibilidad de cambio. Un cuerpo fuera de lo social.

Pero fuera de lo social, cuando lo social se entiende como consenso y equilibrio constante, como un orden genérico inalterable, donde la posibilidad de lo público niega el mundo de lo privado, donde el lugar de lo privado no se reconoce desde y como político. En ese marco, los cuerpos son marginados, transitan invisibles en términos de propuesta política, sin embargo, y siguiendo a Castillo, la posibilidad de cuerpos reunidos puede configurar un propósito, "la asamblea de los cuerpos está constituyendo una política que suspende el pacto político neoliberal y patriarcal de la clase política" (Castillo, 2019, p. 15).

En ese sentido y como lo plantea Fassin, parece necesario reconocer que:

(...) la política se ejerce sobre y por intermedio de los cuerpos. Sobre ellos y en ellos, en particular, se leen las desigualdades, se imprimen las violencias, se inscriben las normas de conducta e inconducta. (...) Repolitizar el mundo es replantear la cuestión de la política y sus fundamentos: la vida, el cuerpo, la moral. La política gobierna vidas, se manifiesta en los cuerpos y procede de elecciones de índole moral. (Fassin, 2018, p. 17)

El movimiento feminista sabe de esos cuerpos, las mujeres han experimentado en y por sus cuerpos el orden social, a costa de sus cuerpos se ha mantenido la organización genérica. Desde los cuerpos el movimiento feminista se constituye. El 
cuerpo como el espacio inmediato, el lugar donde ocurre la violencia en concreto, el lugar donde ocurre lo social.

El cuerpo en protesta y como protesta. La protesta se corporaliza. El cuerpo como espacio político, como territorio de protesta. Cuerpo que interpela y ya no sólo como contingencia, cuerpo como existencia que alcanza al estallido, que formula demandas, que se hace demanda y que demanda. Nada más concreto que el cuerpo, para dejar de ser masa.

Entonces, ese cuerpo negado, ignorado y ahora puesto en escena, propone un nuevo ordenamiento genérico y sacude la política de la conciliación. Su propuesta potencia, creemos, el 18-O y politiza desde un ángulo ignorado, la demanda de cambios. Así, el cuerpo como argumento del 8M no desaparece para la conformación de la protesta y las demandas del estallido, llega al estallido social y lo inunda y lo fortalece. Cuerpo que estalla.

Asimismo, una cierta emocionalidad o afectivismo ronda en las expresiones del $8 \mathrm{M}$. El modo en que son vistas todas las acciones, potencia una visión que sugiere un repliegue de la conformación política tradicional y habitual; insinuando que el componente político de las diversas prácticas no es claramente percibible y por tanto, que prima lo difuso y la posibilidad de indefinición. Sin la razón como garante, sin la razón como reguladora, la noción de lo político se desdibuja. Si hay cuerpo, estamos dentro de lo natural y por tanto, dentro de lo irracional. Se clasificará el movimiento desde esta perspectiva, quitándole la posibilidad de contraparte política válida, en el marco de la emocionalidad expresada y propuesta.

Expresiones y emociones, entonces, que reafirmarían la idea de la despolitización de lo manifestado y de la protesta. Lo anterior, cuando se propone una división afecto y política, entendiendo la política como el espacio de lo racional, de las acciones racionales. El mundo de lo público como el mundo de los no afectos. De la burocratización, de la racionalización, del afuera.

Porque las emociones no pertenecen al terreno de lo social y por tanto, de la política, ajenas a ese espacio, es decir, naturalizadas y asignadas a lo biológico y a lo femenino, por tanto, emociones y afectos, como un obstáculo para el desarrollo del quehacer político, entendido este último como el terreno del logos y la razón.

Asimismo, idea de logos, como oposición a mujer. El logos como la razón, lo universal, lo estable. El logos enfrentado a la masividad del 8M. El logos como el universal y sujeto masculino e individuo y ese mar de mujeres, mar de masividad, incalculable, que desborda, que llena las veredas. Al respecto:

Tengamos presente que además de la naturalización y universalización de las emociones, la supuesta naturaleza irracional y femenina fue otro rasgo de la concepción que definió las emociones desde Darwin (2009) hasta la década de 1980 - 1990, cuando los estudios socioculturales de las emociones -particularmente los trabajos de Luttz y Abu - Lughod, 1990- cuestionaron los significados culturales de la asignación de la vida emocional al mundo femenino. (López, 2016, p. 523) 
Una dicotomía entre razón masculina y emoción femenina donde, como señalan Solana y Vacarezza (2020), se ha establecido una relación entre mujeres, cuerpo y pasiones, para justificar su exclusión de los asuntos llamados públicos. Por lo mismo, fue el movimiento feminista el que ha intentado cuestionar la supuesta neutralidad y la parcialidad de la concepción de política:

Desde su surgimiento, los feminismos desafiaron la concepción de la política como un ámbito de deliberación racional e imparcial, al mismo tiempo que mostraron cómo la distinción entre lo público y lo privado servía para excluir a las mujeres y a otros sujetos culturalmente identificados con el cuerpo y las emociones (Iris Marion Young, 1990). Lejos de limitarse a demandar la inclusión en la vida política o a plantear la igualdad de derechos, los feminismos abogaron, además, por politizar y sacar del confinamiento de lo privado a las emociones, al cuerpo, la sexualidad, la reproducción y el cuidado. Al punto de que los afectos han sido considerados como elementos fundamentales para repensar críticamente la democracia (Chantal Mouffe, 2000) y la justicia (Martha Nussbaum, 2001, 2006). (Solana y Vacarezza, 2020, p. 6)

Pero sabemos que lo político trasciende el estado y sus instituciones, sabemos de lo político en los espacios de lo privado, de los márgenes sociales; más allá de los procedimientos, las articulaciones y los acuerdos. Es en ese marco, también, que podemos entender que los afectos y las emociones están presentes en lo político. En tiempos de protestas, de demandas de cambio, de cuestionamiento a las estructuras, cabe recordar que:

(...) las estructuras no actúan por sí mismas por movimiento espontáneo: "se" las hace mover. ¿Qué es ese "se"? Digamos genéricamente: la política. O sea, dicho de otro modo: las alianzas de fuerzas deseantes. A falta de entrar en el detalle de su formación, se puede al menos decir esto: una crisis, entendida en el sentido "regulacionista", de la transformación de las estructuras del régimen de acumulación, es también un acontecimiento pasional... Ahora bien, no hay transformación de las estructuras sin acción transformadora, es decir, sin acción política, y la acción política es un asunto de afectos y de deseos colectivos: los movimientos de poder (deseantes) determinados (afectivamente) a orientarse en un cierto sentido y a cumplir ciertas cosas para hacer o cambiar una cierta manera sus marcos comunes. (Lordon, 2018, p. 16-17)

Un deseo a la base del cuestionamiento, afectos que afectan la institucionalidad, en el contexto del régimen de acumulación que nos caracteriza. Un, así entendido, acontecimiento pasional, con potencial transformador y trastocador. Un acontecimiento que, reconocemos como parte constitutiva del $8 \mathrm{M}$ y las propuestas del movimiento feminista.

Lo efímero y la inmediatez de ciertas acciones y representaciones, lo no verbal, el cuerpo y la emoción puestas en escena. El cuerpo y las emociones como elementos centrales en la protesta feminista, desde los elementos señalados, esto es, el reconocimiento de lo corporal como un espacio político y de las emociones/afectos 
como manifestaciones que propician cambios. El cuerpo y las emociones como protagonistas. Cuerpo como medio de expresión y emociones que circulan y se colectivizan.

El 18-O como acción colectiva, portando cuerpos y emociones, elementos que el movimiento feminista propone y sostiene. En ese sentido, el estallido social, al que insistentemente se caracterizó como una demanda ilegible, desde la mirada de la performance se hace comprensible. Permite reconocer eso que el movimiento feminista lleva expresando en su constante quehacer y en su permanente decir. Los feminismos han denunciado y demandado democratizar los espacios sociales, pero no sólo los de la vida pública, también han señalado la necesidad de desnaturalizar el espacio de lo privado; en ese esfuerzo, cuerpo y emoción, se han vuelto motivo y vehículo de expresión.

Como propone Oyarzún (2018): "En tanto movimientos sociales y políticos, los feminismos han hecho un largo trayecto en la democratización de nuestro país, así como en las grandes revueltas populares a nivel mundial" (p. 33). Y donde específica y sugiere que:

Se trata de ciudadanías con cuerpo, que dejan atrás los imaginarios cosificadores de las mujeres y el género femenino, propios de nuestra modernidad neocolonial y de concepciones binarias excluyentes de cuerpo 0 alma, sexo o erotismo, masculino o femenino. (Oyarzún, 2018, p. 33)

El estallido social tiene, de este modo, componentes centrales que sostienen y que propone el movimiento feminista. Entonces, cuerpo y emociones como elementos centrales de la performatización de la protesta feminista y esa misma performatización, alcanzando al 18-O. La revuelta feminista, esa que tensionó y tensiona el orden genérico, llega al estadillo y se vuelve parte sustancial de su desarrollo y expresión. Las Tesis, como ejemplo de esa propuesta, con su performance "Un violador en su camino". Emerge el movimiento feminista en el estallido social y lo hace como cuerpo y emociones, desbaratando la idea de excepcionalidad y señalando la performance como un elemento central de las nuevas formas de hacer y estar en la protesta social y como base de un estallido político.

En la presentación y relato del $8 \mathrm{M}$, hay una idea de base asociada al desborde, a lo corporal, a lo emocional. En esa asociación, el imprevisto vale de argumento, para suponer transitoriedad y para suponer falta de profundidad política y de continuidad. Sin embargo esa transitoriedad, esa expresión festiva, ese momento de expresiones, no quedó del lado de lo excepcional. La movilización hizo camino, se instituyó en el estallido, el cuerpo y las emociones alcanzaron el estallido, el feminismo, los feminismos, alcanzaron el estallido y lo dotaron de contenidos y no sólo de formas. Lo que se asumió temporal, excepcional y fortuito de la acción política de los feminismos, en sus expresiones concretas del 8M y las tomas universitarias, alcanzó al estallido.

\section{Reflexiones finales}

Entendemos el 18-O como un acontecimiento que rompe con la habitualidad, en el marco de la emergencia de una serie de sucesos que cuestionan relaciones y órdenes sociales, económicos y políticos. Sin embargo, este acontecimiento está 
vinculado a un ensamblaje de fuerzas anteriores, que tienen como referente movimientos previos, en este caso, asociados al feminismo. En ese sentido, la propuesta feminista, entendida como un continuo, aunque con diferentes énfasis e intencionalidades, se constituye en una base que alcanza el llamado "estallido social", potenciando una irrupción no singularizante.

Una irrupción en términos de acontecimiento, que siendo situada no se agota en lo contingente. Así, proponemos que el feminismo puede ser entendido como un hilo de continuidad, que permite hacer inteligible esta serie de sucesos que, de otra manera, no podrían ser interpretados. Las nuevas formas de ser de la política y las nuevas formas de hacer política, que están emergiendo, como esta politización no institucional a la que aludimos y la performatización de las protestas, parecen dar cuenta de una cierta alteración que -por lo mismo-, aparece con límites difusos.

Ronda, entonces, una cierta incertidumbre, un proceso que no parece concluido y que no permite lecturas definitivas, un final abierto que, por lo mismo, genera un vértigo que agita el recetario de las respuestas conocidas, esas mismas que son desbordadas porque no logran dar cuenta de las demandas que emergen de estos nuevos sentidos de la política, o de estas vidas repolitizadas, de estos cuerpos y emociones políticamente transformadores.

Asimismo, la ausencia de identidad como una matriz que preconfigura movimientos y relaciones se vuelve posible. Un entramado de experiencias reconocibles, pero que no logran ser clasificadas dentro de una misma categoría, un conjunto de demandas que no pueden homogeneizarse, aunque remitan a una causa común: una formación económica, sociocultural y política generadora de desigualdad, la formación social capitalista en su materialización neoliberal. Una ausencia de identidad relacionada con estas subjetividades políticas que se están fraguando y que podemos intuir, vislumbrar, pero no asir.

Estos dos elementos parecen incluidos en la idea de desborde, que se evidencia en los marcos institucionales actuales y el proceso de cambio que los caracterizaría. Un desborde de las demandas que rebasa los límites de la institucionalidad política y un desborde del cuerpo y las emociones como elementos siempre negados y ahora puestos en el terreno de la disputa y el poder que ordena; un desborde de formas de hacer políticas excluyentes, desborde transformador, de estructuras y subjetividades.

Ahora bien, resulta necesario precisar que el movimiento feminista no es homogéneo y que, en ese sentido, no se plantea desde un carácter siempre cuestionador del orden actual. Sabemos de las diferencias posibles, asociadas a sus diversas vertientes o a sus distintos acentos, en un eventual continuo que puede ir desde las versiones más liberales a aquellas contrahegemónicas. Sin embargo, para este análisis hemos considerado el movimiento feminista como un quehacer que pretende cuestionar la naturalización de las relaciones sociales y visibilizar la posibilidad de cambios.

De este modo, pensamos que es posible considerar la presencia de nuevas formas de entender y experimentar la ciudadanía y la política, a las que ha contribuido 
el feminismo, además de otros movimientos y procesos sociales - como las migraciones -. Un "estallido social" que visualiza esa emergencia, con la idea de sujetos que movilizan instituciones, pero que -sabemos- están dentro de condiciones materiales de existencia y que, por lo mismo, mantienen una posición en la estructura social, en medio de procesos de diferenciación y de desigualdad social. Tal vez en esta oportunidad, como en otras, tengamos que observar el modo en que estructuras y sujetos se tensionan mutuamente.

\section{Referencias bibliográficas}

Archivo Nacional de Chile (s/f). El movimiento feminista del 2018. https://www.archivonacional.gob.cl/616/w3-article93703.html?_noredirect=1. Acceso en: 13/3/2021.

Basuare, M. \& Joignant, A. (2019, octubre 29). Las raíces de la conflictividad y radicalización de la protesta en Chile: lo que sabemos y lo que no. Ciper académico. https://www.ciperchile.cl/2019/10/29/las-raices-de-laconflictividad-y-radicalizacion-de-la-protesta-en-chile-lo-que-sabemos-y-loque-no/. Acceso en 17/10/2020.

Candina Polomer, A. (2019). La clase media que no era: ira social y pobreza en Chile. En Artaza et al., Chile despertó. Lecturas desde la Historia del estallido social de octubre (53-58). Universidad de Chile.

Castillo, A. (2018). De la revuelta feminista, la historia y Julieta Kirkwood. En F. Zerán (Ed.), Mayo feminista. La rebelión contra el patriarcado (35-58). LOM.

Castillo, A. (2019). Asamblea de los cuerpos. Sangría.

Castro, E. (2004). El vocabulario de Michel Foucault. Un recorrido alfabético por sus temas, conceptos y autores. Prometeo y Universidad Nacional de Quilmes.

Citro, S. (2009). Cuerpos significantes. Travesías de una etnografía dialéctica. Biblos.

CNN Chile (2019, 7 de diciembre). 10 Postales del 2018 feminista, el año que las mujeres alzaron la voz en todo el país, CNN Chile. https://www.cnnchile.com/ladecada-noticias/10-postales-2018-

feminista_20191207/. Acceso en: 15/3/2020. 
Coordinadora Feminista 8M (2019, febrero 28). ¡Estas son las diez demandas con las que vamos a la Huelga General Feminista! https://cf8m.cl/estas-son-lasdiez-demandas-con-las-que-vamos-a-la-huelga-general-feminista/. Acceso en: $21 / 8 / 2020$.

Desconcierto (2019, 9 de marzo). «LA movilización más grande de la historia»: Coordinadora $8 \mathrm{M}$ realiza balance de huelga feminista y cifra en $800 \mathrm{mil}$ mujeres movilizadas. El Desconcierto. https://www.eldesconcierto.cl/2019/03/09/la-movilizacion-mas-grande-dela-historia-tiene-rostro-de-mujer-coordinadora-8m-realiza-balance-dehuelga-feminista-y-cifra-en-800-mil-mujeres-movilizadas-a-nivel-nacional/. Acceso en: 22/6/2020.

Fassin, D. (2018). Por una repolitización del mundo. Las vidas descartables como desafío del siglo XXI. Siglo XXI Editores.

De Fina, D. y Figueroa, F. (2019). Nuevos "campos de acción política" feminista: Una mirada a las recientes movilizaciones en Chile. Punto Género, 11, pp.5172.

Follegatti, L. (2018) El constante aparecer del movimiento feminista. Reflexiones desde la contingencia. En F. Zerán (Ed.), Mayo feminista. La rebelión contra el patriarcado (77-97). LOM.

Follegatti, L. (2020). ¿Qué democracia? Feminismo y política en el Chile de los 80s. Revista de Sociología, (35)1, pp.56-68.

Insunza, I. y Pérez, S. (2020). La revuelta simbólica: entre el texto y los cuerpos. Revista Hiedra. https://revistarizoma.com/2020/10/09/la-revuelta-simbolicaentre-el-texto-y-los-cuerpos/. Acceso en 15/10/2020.

Kirkwood, J. (2019). Feminismo y participación política en Chile. En J. Kirkwood, Escritos feministas. La vigencia del pensamiento de Julieta Kirkwood en el Chile actual (113-144). Universitaria-FLACSO.

La Tercera (2018, 8 de mayo). Las demandas tras las tomas feministas en universidades. La Tercera. https://www.latercera.com/nacional/noticia/lasdemandas-tras-las-tomas-feministas-universidades/157888/. Acceso en: 13/1/2020. 
La Tercera (2019, 8 de marzo). Ellas marcharon en todo Chile y fijan un hito en el 8M. La Tercera. https://www.latercera.com/nacional/noticia/ellas-marcharonchile-fijan-hito-8m/562307/. Acceso en: 2/3/2020.

Le Breton, D. (2002). Antropología del cuerpo y modernidad. Nueva Visión.

López, Oliva (2016). Los significados médicos de las emociones en las enfermedades psiquiátricas en México. La histeria y la epilepsia (1900 - 1930). En M. Ariza (Coord.), Emociones, afectos y sociología: diálogos desde la investigación social y la interdisciplina (521-544). UNAM.

Lordon, F. (2018). La sociedad de los afectos: por un estructuralismo de las pasiones. Adriana Hidalgo Editora.

Meccia, E. (2016). El tiempo no para. Los últimos homosexuales cuentan la historia. Eudeba y Ediciones UNL.

Miranda Leibe, L. y Roque López, B. (2019). El Mayo Estudiantil Feminista de 2018 en la Pontificia Universidad Católica de Chile. 'La Revolución es Feminista'. En Larrondo y C. Ponce Lara (Eds.), Activismos feministas jóvenes: emergencias, actrices y luchas en América Latina (59-78). CLACSO.

Navarro, F. (2018, junio 13) Escribiendo la revolución feminista en educación superior. Ciper Chile. https://ciperchile.cl/2018/06/13/escribiendo-la-revolucionfeminista-en-educacion-superior/. Acceso en: 23/4/2020.

Oyarzún, K. (2018). Feminismos Chilenos: Una democratización encarnada. Revista Anales, Séptima serie, 14, pp.33-50.

Oyarzún, K. (2020). Unidad Popular: genealogías feministas interseccionales. En Austin Henry et al. (Comps.), La vía chilena al socialismo: 50 años después (31-61). CLACSO.

Pinto Molina, M. (1989). Introducción al análisis documental y sus niveles: el análisis de contenido. Boletín de la ANABAD, (39)2, pp.323-342. 
Revista Punto Género N․ 16 Diciembre de 2021

ISSN 2735-7473 / 194- 218

Programa de las Naciones Unidas para el Desarrollo (2019). Diez años de auditoría a la democracia: Antes del estallido. PNUD.

Ponce, C. (2020). El movimiento feminista estudiantil chileno de 2018: Continuidades y rupturas entre feminismos y olas globales. Izquierdas, 49, pp.1554-1570.

Rancière, J. (2006). Política, policía, democracia. LOM.

Red Chilena Contra la Violencia Hacia Las Mujeres (2019, noviembre 6). Estallido social desde una perspectiva feminista. The Clinic. https://www.theclinic.cl/2019/11/06/estallido-social-desde-una-perspectivafeminista/. Acceso en: 30/5/2020.

Reyes-Housholder, C. y Roque, B. (2019). Desafíos al poder de género desde la calle hasta la Moneda. Revista de Ciencia Política, (39)2, pp.191-215.

Richard, N. (2018). La insurgencia feminista de mayo 2018. En F. Zerán (Ed.), Mayo feminista. La rebelión contra el patriarcado (115-125). LOM.

Scribano, Adrián (2017). Amor y acción colectiva: una mirada desde las prácticas intersticiales en Argentina. Aposta. Revista de Ciencias Sociales, 74. https://www.redalyc.org/jatsRepo/4959/495954961010/html/index.html\#fn2. Acceso en: 23/7/2020.

Scribano, A., Cena, R. \& Peano, A. (2012). Políticas de los cuerpos y emociones en los sujetos involucrados en acciones colectivas en la ciudad de Villa María, 2001-2008. Papeles del CEIC, (12)1, pp.1-37. http://www.identidadcolectiva.es/pdf/77.pdf

Segovia, M. (2020, marzo 6). El movimiento feminista: la resistencia al sistema político que precipitó la Revuelta de Octubre y que pone en jaque al Gobierno. El Mostrador. https://m.elmostrador.cl/noticias/pais/2020/03/06/el-movimientofeminista-el-eje-central-de-resistencia-al-sistema-politico-que-precipito-larevuelta-de-octubre-y-que-pone-en-jaque-al-gobierno/. Acceso en: $17 / 9 / 2020$.

Solana, M. y Vacarezza, N. L. (2020). Sentimientos feministas. Estudos Feministas, (28)2, e72445. 
Revista Punto Género N․ 16 Diciembre de 2021

ISSN 2735-7473 / 194- 218

Taylor, D. (2015). El Archivo y el repertorio. La memoria cultural performática en las Américas. Ediciones Universidad Alberto Hurtado.

Urzúa Martínez, S. (2019). Aportes a una etnografía de los movimientos feministas: recursos expresivos en las marchas \#Ni una menos y \#8M en Santiago de Chile. Antípoda. Revista de Antropología y Arqueología, 35, pp.115-124.

Waissbluth, M. (2020). Orígenes y evolución del estallido social en Chile. Universidad de Chile.

Zerán, F. (2018). Prólogo. En F. Zerán (Ed.), Mayo feminista. La rebelión contra el patriarcado (9-20). LOM. 